\title{
Development and Validation of Veratric Acid in Tabebuia avellanedae using Liquid Chromatography-Electrospray Ionization-Mass Spectrometry/Mass Spectrometry-Multiple Reaction Monitoring-Based Assay Coupled with 1,1-Diphenyl-2-Picrylhydrazyl Method
}

\author{
Puttaswamy Naveen, Harakanahalli Basavegowda Lingaraju', Siddappa Chandrappa', Srikant Anitha, \\ Kodimule Shyam Prasad'
}

Analytical Research and Development, Vidya Herbs Pvt. Ltd, 'Phytochemistry Lab, Vidya Herbs Pvt. Ltd, Bangalore, Karnataka, India

\begin{abstract}
Objective: The aim of the present study is to develop a new simple, precise, and accurate liquid chromatography-tandem mass spectrometry (LC-MS/MS) method for the quantification of veratric acid in Tabebuia avellanedae Linn. Materials and Methods: The quantification of veratric acid was done using collision-induced dissociation multiple reaction monitoring scan of mass spectrometry technique. The developed method was validated according to the International Conference on Harmonization guidelines. The free radical scavenging activity was performed by 1,1-diphenyl-2-picrylhydrazyl (DPPH) method. Results: The ion transitions of the precursor to the productions were principally protonated ion $[\mathrm{M}+\mathrm{H}]^{+}$ at $\mathrm{m} / \mathrm{z} 182.8>139.20,124.20$, and 77.0 for veratric acid. The proposed method was validated for linearity with an excellent correlation coefficient of 0.9978 . The intraday and intermediate precisions and repeatability showed the percentage relative standard deviation was $<2 \%$. The accuracy for the determination of veratric acid was within $82.20 \%-97.65 \%$. The limit of detection and limit of quantitation were 0.66 and 2.21 ppm, respectively. The half-maximal inhibitory concentration value for the DPPH radical scavenging activity of ascorbic acid and quality control sample (hydroalcoholic extract of $T$. avellanedae) was found to be 17.79 and $36.44 \mu \mathrm{g} / \mathrm{ml}$, respectively. Conclusion: The developed LC-MS/MS method is a simple, rapid, precise, accurate, and it is recommended for efficient assays in routine work. T. avellanedae exhibited strong DPPH radical scavenging activity.

Key words: 1,1-diphenyl-2-picrylhydrazyl, method validation, multiple reaction monitoring, Tabebuia avellanedae, veratric acid

\section{SUMMARY}

- The objective of the present study is to develop a new simple, precise, and accurate liquid chromatography-tandem mass spectrometry method for the quantification of veratric acid in Tabebuia avellanedae. The developed method was validated according to the requirements for the International Conference on Harmonisation guidelines. The structural characterization of veratric acid was studied based on the accurate mass $(\mathrm{m} / \mathrm{z})$ and ion transitions. T. avellanedae exhibited good DPPH-free radical scavenging property.
\end{abstract}

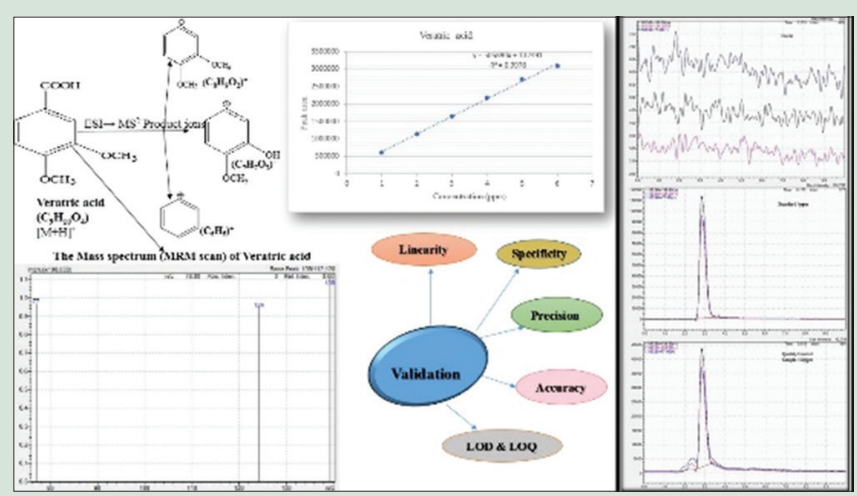

Abbreviations Used: LC-MS/MS: Liquid Chromatography-Tandem Mass Spectrometry, ICH: International Conference on Harmonisation, DPPH: 1,1-diphenyl-2-picrylhydrazyl, $r^{2}$ : Correlation coefficient, WHO: World Health Organization, $\mathrm{IC}_{50}$ : Half maximal inhibitory concentration, WHO: World Health Organization, ppm: Parts per million, \% RSD: Percentage relative standard deviation, MRM: Multiple reaction monitoring, ESI: Electrospray ionization, $\mu \mathrm{m}$ : Micrometer, $\mu$ : Microliter, mm: Millimeter, ml: Milliliter, min: Minute, CID: Collision-induced dissociation, $\mathrm{A}^{0}$ : Angstrom, ms: Millisecond, eV: Electronvolt, $\mathrm{V}$ : Volt, ${ }^{\circ} \mathrm{C}$ : Degree Celsius, Kv: Kilovolt, kPa: Kilopascal, DL: Desolvation line, $\mu \mathrm{g}$ : Microgram, LOD: Limit of detection, LOQ: Limit of quantification, USP: United States Pharmacopoeia.

Correspondence:

Dr. Puttaswamy Naveen,

Analytical Research and Development, Vidya Herbs Pvt. Ltd., Jigani, Anekal Taluk, Bengaluru, Karnataka, India.

E-mail: naveen@vidyaherbs.com DOI: $10.4103 /$ pr.pr_77_19

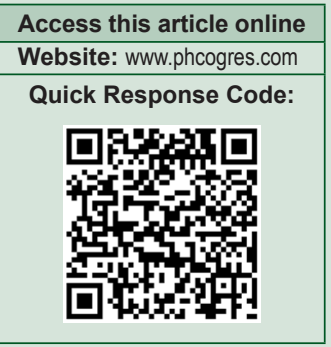

\section{INTRODUCTION}

Herbal medicines, also called phytomedicines or phytotherapy, refer to herbs, herbal materials, herbal preparations and finished herbal products that contain parts of plants as active ingredients that can be used to promote health and treat diseases. ${ }^{[1]}$ In the $21^{\text {st }}$ century, people are prone to various diseases based on their way of living and occupational habits. In 2013, the World Health Organization (WHO) developed and launched "WHO Traditional Medicine Strategy 2014-2023" and emphasized the need to integrate traditional and complementary medicine to promote universal healthcare and to ensure the quality, safety, and effectiveness of

This is an open access journal, and articles are distributed under the terms of the Creative Commons Attribution-NonCommercial-ShareAlike 4.0 License, which allows others to remix, tweak, and build upon the work non-commercially, as long as appropriate credit is given and the new creations are licensed under the identical terms.

For reprints contact: reprints@medknow.com

Cite this article as: Naveen P, Lingaraju HB, Chandrappa S, Anitha S, Prasad KS. Development and validation of veratric acid in Tabebuia avellanedae using liquid chromatography-electrospray ionization-mass spectrometry/mass spectrometry-multiple reaction monitoring-based assay coupled with 1,1-diphenyl2-picrylhydrazyl method. Phcog Res 2020;12:107-11. 
such medicine. ${ }^{[2]}$ Quality control of herbal medicines targets to safeguard their consistency, safety, and efficacy.

T. avellanedae (L.) is a tree belonging to the family Bignoniaceae from the tropical rain forests of certain South America from Brazil to northern Argentina. The inner bark of this tree is also known as Taheebo ${ }^{[3]}$ has traditionally folk medicines for treating against various pathogenic and disease conditions. ${ }^{[4]}$ The major phytochemicals present in T. avellanedae that have been isolated include flavonoids, ${ }^{[5,6]}$ iridoids, ${ }^{[5]}$ coumarins, ${ }^{[6]}$ anthraquinone-2-carboxylic acid, ${ }^{[7]}$ cyclopentene derivatives ${ }^{[8]}$ benzoic acid derivatives, ${ }^{[5,6]}$ benzaldehyde derivatives, ${ }^{[6]}$ $\beta$-lapachone ${ }^{[9-11]}$ and quinones $^{[4]}$ together with anthraquinones, ${ }^{[5]}$ furanonaphthoquinones, ${ }^{[3]}$ and naphthoquionones. ${ }^{[12,13]}$ T. avellanedae has been reported for antiradical scavenging (unpublished data), anti-infectious, ${ }^{[12]}$ anticancer, ${ }^{[14]}$ anti-inflammatory, ${ }^{[15,16]}$ antibacterial, ${ }^{[17]}$ and antiulcer. ${ }^{[18]}$

\section{MATERIALS AND METHODS}

\section{Materials}

Veratric acid (3,4-dimethoxy benzoic acid), used as standard (HPLC grade 99.6\%), was procured from Sigma-Aldrich (India). All reagents and solvents were of analytical and liquid chromatography-tandem mass spectrometry (LC-MS) grade. The dried powdered bark material of T. avellanedae was procured from South Korea.

\section{Preparation of veratric acid standard stock solution}

Accurately weighed an appropriate amount of veratric acid reference standard was taken and dissolved in $70 \%$ methanol in a $50 \mathrm{ml}$ volumetric flask to obtain a stock solution of $100 \mathrm{ppm}$. Before analysis, the solution was filtered through $0.20 \mu \mathrm{m}$ nylon membrane filters.

\section{Preparation of quality control (taheebo extract) sample solution}

The quality control sample (hydroalcoholic extract of T. avellanedae) was prepared in $70 \%$ methanol to achieve the final concentration of $600 \mathrm{ppm}$ and make diluted to $100 \mathrm{ppm}$. Prior to analysis, the solution was filtered through $0.20 \mu \mathrm{m}$ nylon membrane filters.

\section{Preparation of spiked sample}

A spiked sample is a sample prepared by adding a known quantity of analyte (veratric acid standard solution) to a sample solution (matrix). Three different volumes $(0.3,0.4$, and $0.5 \mathrm{ml})$ of veratric acid standard stock solution $(100 \mathrm{ppm})$ were added to the sample solution $(100 \mathrm{ppm})$. Prior to analysis, the solutions were filtered through $0.20 \mu \mathrm{m}$ nylon membrane filters.

\section{Instrumentation and chromatographic conditions}

Veratric acid was quantified using triple quadrupole mass spectrometry (LC-MS/MS-8050, Shimadzu, Japan) equipped with electrospray ionization (ESI) source operating in positive ionization mode. Nitrogen was used as nebulizer, drying, and heating gas. Argon gas was used for the collision-induced dissociation (CID) gas. The separation was carried out in Kinetex $\mathrm{C}_{18}$ column $(100 \AA$, $2.6 \mu \mathrm{m}, 150 \mathrm{~mm} \times 2.1 \mathrm{~mm})$ at a flow rate of $0.2 \mathrm{ml} / \mathrm{min}$ in ESI source. The mobile phase consisted of $0.1 \%$ formic acid: methanol $(\mathrm{A}: \mathrm{B})=50: 50$ with isocratic elution and the injection volume of $5 \mu \mathrm{l}$. All solutions were degassed and filtered through $0.2 \mu \mathrm{m}$ pore size filter. The column was maintained at $40^{\circ} \mathrm{C}$ throughout the analysis. $70 \%$ methanol used as a diluent, and the total run time was $10 \mathrm{~min}$. The MS chromatographic conditions used in the study as follows: nebulizer gas flow, $3 \mathrm{~L} / \mathrm{min}$; drying gas flow, $10 \mathrm{~L} / \mathrm{min}$; and heating gas flow, $10 \mathrm{~L} / \mathrm{min}$. The interface voltage and CID gas pressure were set at
$4 \mathrm{Kv}$ and $270 \mathrm{kPa}$. The interface temperature was maintained at $300^{\circ} \mathrm{C}$, while desolvation line and heat block temperature were maintained at 250 and $400^{\circ} \mathrm{C}$, respectively, in ESI source. Other parameters were tuned automatically. The MS parameters were optimized by direct injection of $1 \mathrm{ppm}$ of standard. The ion transitions of the precursor to the product ion and their CID energy were as follows: the protonated ions $[\mathrm{M}+\mathrm{H}]^{+}$ at $\mathrm{m} / \mathrm{z} 182.80 \rightarrow 139.20$ ion as a quantifier (collision energy, $-15 \mathrm{eV}$; dwell time, $100 \mathrm{~ms}$; Q1 pre-Bias, $-12 \mathrm{~V}$; Q3 pre-Bias, $-29 \mathrm{~V}$ ), $182.80 \rightarrow 124.20$ ion as a qualifier-1 (collision energy, $-17 \mathrm{eV}$; dwell time, $100 \mathrm{~ms}$; Q1 pre-Bias, $-12 \mathrm{~V}$; Q3 pre-Bias, $-25 \mathrm{~V}$ ), and $182.80 \rightarrow 77.00$ ion as a qualifier-2 (collision energy, $-30 \mathrm{eV}$; dwell time, $100 \mathrm{~ms}$; Q1 pre-Bias, $-12 \mathrm{~V}$; Q3 pre-Bias, $-28 \mathrm{~V}$ ) for veratric acid.

Quantification was performed by multiple reaction monitoring (MRM) method of protonated precursor ions and related product ions by monitoring $182.80 \rightarrow 139.20$ only one quantifier transition and peak areas for veratric acid. Peak identification was based on the retention time, and the sample ion chromatograms must fully overlap with the standard. The MS data were processed by LabSolution software.

\section{The characterization of product ions using MS/MS}

In this study, the characterization was established by injecting an individual solution of $4 \mathrm{ppm}$ of veratric acid standard and quality control sample $(100 \mathrm{ppm})$ respectively into the tandem mass spectrometry. Precursor and product (fragmentation) ions were checked by MRM of positive ionization mode. Major peaks in the MS/MS spectrum were used to quantify the compounds.

\section{Validation of the method}

In the present study, the isocratic LC-MS/MS method was developed according to the International Conference on Harmonisation (ICH) guidelines. ${ }^{[19]}$ The method is validated for specificity, linearity, precision, repeatability, accuracy, limit of detection, and limit of quantification.

\section{Specificity}

The specificity of the LC-MS/MS method is demonstrated by the separations of the analytes from other potential components such as impurities, degradants, or excipients. In this study, the specificity was demonstrated by running a blank, veratric acid standard (4 ppm), and quality control sample solution (100 ppm). In addition, the tailing factor and theoretical plates are determined.

\section{Linearity}

Linearity was determined by injecting individual known concentrations of veratric acid standard solution in triplicate by diluting the standard stock solution. The standard solutions were injected, and the peak area was measured. For linearity study, six aliquots in the range $0.1-0.6 \mathrm{ml}$ of standard stock solution (i.e., $100 \mathrm{ppm}$ ) were taken and diluted to $10 \mathrm{ml}$ to obtain concentrations in the range of 1-6 ppm.

\section{Precision}

Precision was determined by studying the intraday precision, sample repeatability, and intermediate precision. The intraday precision and intermediate precision were determined at a minimum of three different concentration levels $(3,4$, and $5 \mathrm{ppm})$ of veratric acid standard at six replicates. The repeatability was determined at a minimum of ten replicates at $100 \%$ of the test concentration. The intermediate precision was carried for another day by a different analyst. Precision was evaluated based on the percentage relative standard deviation (\%RSD) value. 


\section{Accuracy}

The accuracy of the method was tested by adding standard solutions into the sample solution (standard addition method). The veratric acid standard stock solution was spiked into the samples to determine recovery. Three different volumes $(0.3,0.4$, and $0.5 \mathrm{ml})$ of veratric acid standard stock solution $(100 \mathrm{ppm})$ were added to the sample solution $(100 \mathrm{ppm})$. Triplicate injections were made with all the spiked samples.

$\%$ of recovery $=(b-a) / c \times 100$.

Where ' $a$ ' is the amount of drug found in the sample before the addition of standard drug.

' $b$ ' is the amount of drug found after the addition of standard drug.

' $c$ ' is the amount of standard drug added.

\section{1,1-diphenyl-2-picrylhydrazyl radical scavenging activity}

The free radical scavenging capability of ascorbic acid and quality control sample (Taheebo extract) was determined using 1,1-diphenyl-2-picrylhydrazyl (DPPH) according to the previously described method. ${ }^{[20]}$ Weighed appropriate amount of ascorbic acid (99\% pure) and quality control sample were taken in a $100 \mathrm{ml}$ volumetric flask. Dissolved by adding methanol solution to get a concentration of $100 \mu \mathrm{g} / \mathrm{ml}$ and then further diluted to $5,10,15,20$, and $25 \mu \mathrm{g} / \mathrm{mL}$. $1.0 \mathrm{ml}$ aliquot of each dilution standard ascorbic acid $(100 \mu \mathrm{g} / \mathrm{ml})$ and quality control sample were taken in a test tube and was added to $1 \mathrm{ml}$ of $0.5 \mathrm{mM}$ DPPH (methanol). The standard and samples were kept at room temperature in the dark for $30 \mathrm{~min}$, and the absorbance was measured at $517 \mathrm{~nm}$ spectrometrically (Shimadzu, Japan). The percentage of DPPH radical scavenging activity was calculated as follows:

Inhibition $(\%)=[(\mathrm{Ao}-\mathrm{Ae}) / \mathrm{Ao}] \times 100$.

Where Ao is the absorbance of the control.

Ae is the absorbance of the extract/standard.

\section{Statistical analysis}

Results were expressed as mean \pm standard deviation. The data were submitted to statistical analysis using excel software.

\section{RESULTS AND DISCUSSION}

The optimization of chromatographic conditions was achieved by increasing the signal intensity, peak shape, and also improving the protonation or deprotonation (ionization) of the analyte. Methanol leads the lower baseline absorbance, background noise, and high sensitivity of the analysis. The use of isocratic mobile phase $0.1 \%$ formic acid (A) and methanol (B) (A:B: 50:50 v/v) providing the proper retention time and higher response of the analyte.

Electrospray ionization exhibited a higher intensity of the analyte in the positive ion mode compared to negative ionization mode. MRM was successfully developed for the veratric acid. MRM spectrum for veratric acid was shown in Figure 1. The structural characterization of veratric acid was based on the accurate mass $(\mathrm{m} / \mathrm{z})$, retention recorded time, recorded ion transitions, and literature data. The ion transitions of the precursor to the product ions were principally protonated ion $[\mathrm{M}+\mathrm{H}]^{+}$at $\mathrm{m} / \mathrm{z} 182.8$. The major product ions at $\mathrm{m} / \mathrm{z}$ $139.20\left(\mathrm{C}_{8} \mathrm{O}_{2} \mathrm{H}_{9}\right)^{+}, 124.20\left(\mathrm{C}_{7} \mathrm{O}_{2} \mathrm{H}_{7}\right)^{+}$and $77.0\left(\mathrm{C}_{6} \mathrm{H}_{5}\right)^{+}$were yielded by successive loss of $-\mathrm{COOH}$ group, $-\mathrm{CH}_{2}, \mathrm{COOH}$ groups and $-\mathrm{COOH}$, $\mathrm{CH}_{3} \mathrm{OH}, \mathrm{CH}_{3} \mathrm{OH}\left(\mathrm{C}_{3} \mathrm{H}_{6} \mathrm{O}_{4}\right)$ groups from $[\mathrm{M}+\mathrm{H}]^{+}$ions, respectively. Neither sodium nor solvent adducts were observed. By comparing the ion transitions with the authentic reference standard material and also comparing with the NIST Tandem (MS/MS) Library (NIST Number 1176575), it was clearly identified as veratric acid.

A method validation study is carried out to establish the method's performance. In specificity, the retention time of veratric acid reference standard was found to be $2.853 \mathrm{~min}$. The mass chromatogram of test sample confirms the presence of veratric acid at $2.853 \mathrm{~min}$ without any interferences [Figure 2]. The mass chromatogram of the sample solution overlay with the standard solution, so the method is specific. The chromatographic parameters such as column efficiency and peak symmetry were done to the standard solution according to the $\mathrm{ICH}$ guidelines. The theoretical plates and the tailing factor were found to be 2907 (theoretical plates/meter) USP and 1.5, respectively, indicated that column efficiency was satisfactory. The calibration plots were linear in the range $1,2,3,4,5$, and $6 \mathrm{ppm}$, and the correlation coefficient $\left(r^{2}\right)$ of veratric acid is 0.9978 , as shown in Figure 3. The $r^{2}$ value is greater than 0.990 . This indicates that the good fitting of the curve. The method has good linearity corresponds to peak area on concentrations. The minimum acceptable correlation coefficient is $0.990 .{ }^{[21]}$ The data pertaining to the intraday precision and intermediate precision were summarized in Table 1 . In intraday precision, the \% RSD of peak area of veratric acid standard concentration of 3, 4, and $5 \mathrm{ppm}$ was found to be $1.073 \%, 0.963 \%$, and $0.604 \%$, respectively. In intermediate precision, the RSD of peak area of veratric acid standard concentration

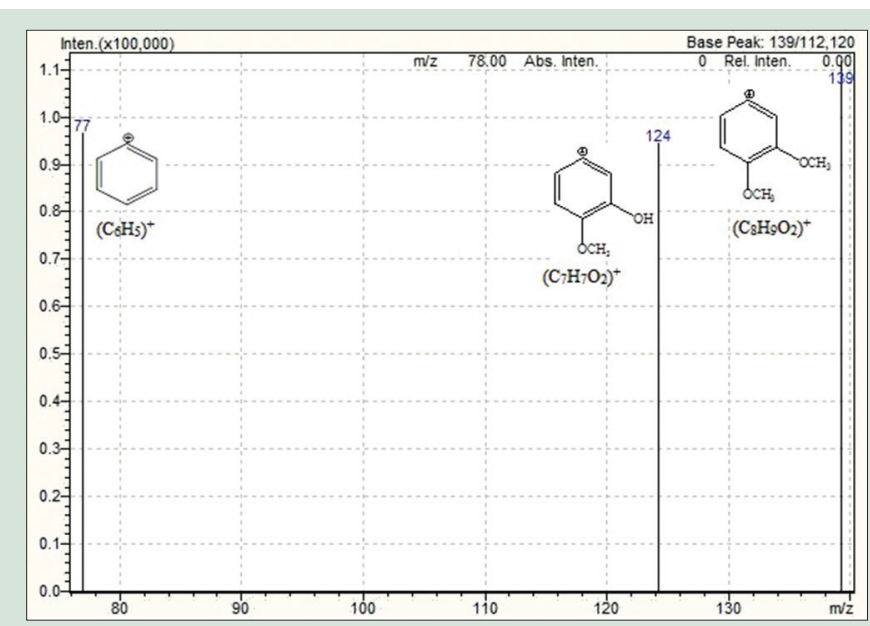

Figure 1: The Mass spectrum (multiple reaction monitoring scan) of veratric acid standard. The veratric acid showed a $\left[\mathrm{M}+\mathrm{H}^{+}\right.$peak at $\mathrm{m} / \mathrm{z}$ 182.8. The corresponding $\mathrm{MS}^{2}$ product (fragment) ions of veratric acid is $\mathrm{m} / \mathrm{z} 139.20,124.20$ and 77.0

Table 1: Intra- and inter-day precision studies of veratric acid

\begin{tabular}{|c|c|c|c|c|c|c|}
\hline \multirow{2}{*}{$\begin{array}{l}\text { Veratric acid standard } \\
\text { concentration (ppm) }\end{array}$} & \multicolumn{3}{|c|}{ Intraday precision } & \multicolumn{3}{|c|}{ Intermediate precision } \\
\hline & Mean area & SD & Percentage RSD & Mean area & SD & Percentage RSD \\
\hline 3 & 1496264 & 16052 & 1.073 & 1118799 & 20050 & 1.792 \\
\hline 4 & 1994785 & 19211 & 0.963 & 1469684 & 12884 & 0.877 \\
\hline 5 & 2482164 & 14995 & 0.604 & 1821808 & 6444 & 0.354 \\
\hline
\end{tabular}

n=6. SD: Standard deviation; RSD: Relative standard deviation 
Table 2: Recovery study of veratric acid

\begin{tabular}{lccccccc}
\hline \multicolumn{7}{c}{ Recovery study of Veratric acid } \\
\hline Amount added $(\mathrm{ppm})$ & Mean area $(\mathrm{b})$ & SD & Percentage RSD & a & c & Percentage recovery \\
\hline 3 & 1890272 & 10884 & 0.576 & 669529 & 1339878 & $82.20 \%$ \\
4 & 2439881 & 16499 & 0.676 & 669529 & 1812930 & $97.65 \%$ \\
5 & 2831468 & 16547 & 0.584 & 669529 & 2271601 & $95.17 \%$ \\
\hline
\end{tabular}

$n=3$. SD: Standard deviation; RSD: Relative standard deviation

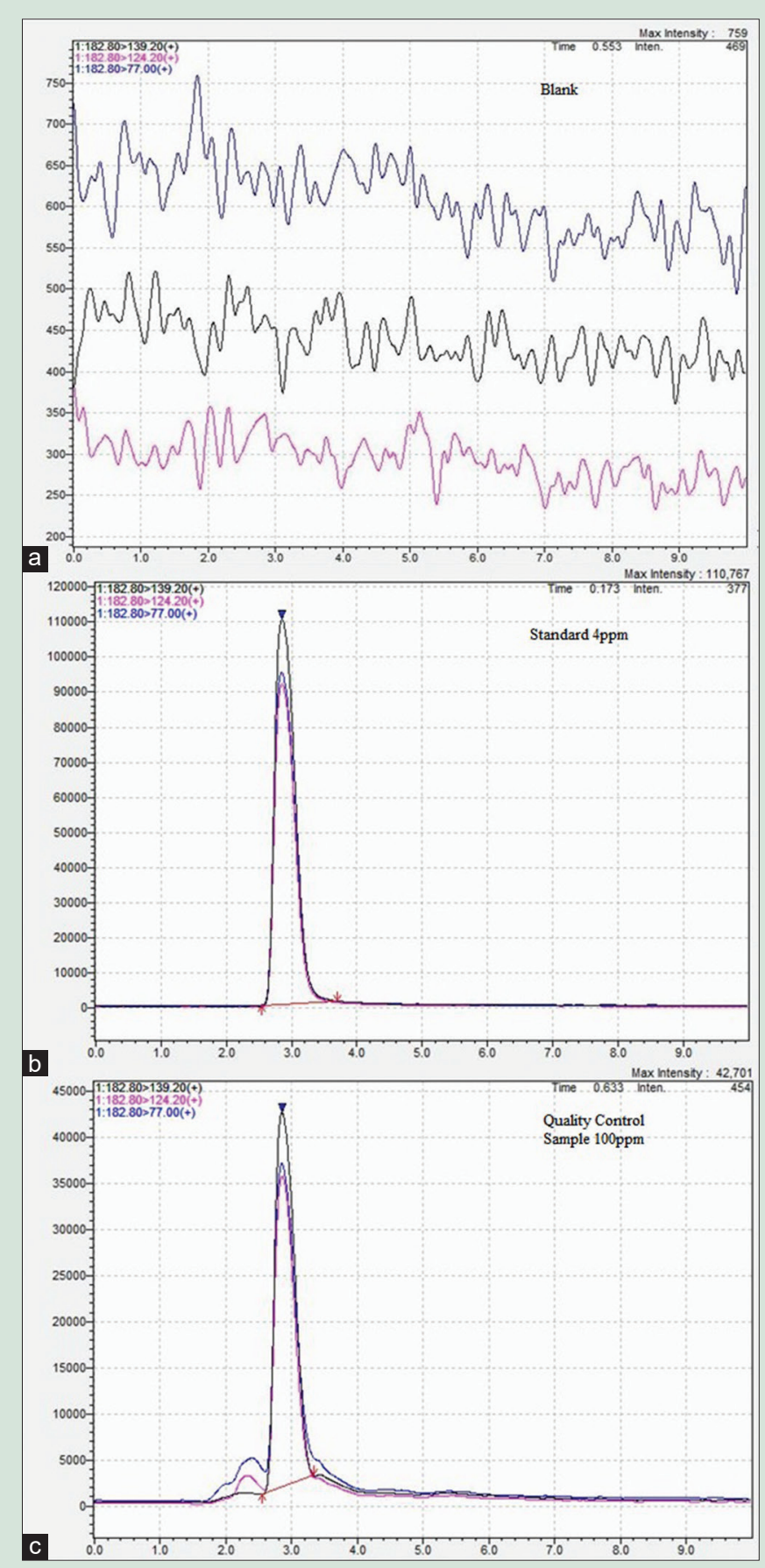

Figure 2: Optimized mass chromatogram of veratric acid (a) blank (b) standard (4 ppm) (c) quality control sample (100 ppm)

of 3 , 4, and 5 ppm was found to be $1.792 \%, 0.877 \%$ and $0.354 \%$, respectively. In repeatability, the $\%$ RSD of peak area of the quality control sample (Taheebo extract) of $100 \mathrm{ppm}$ was found to be $0.656 \%$. The $\%$

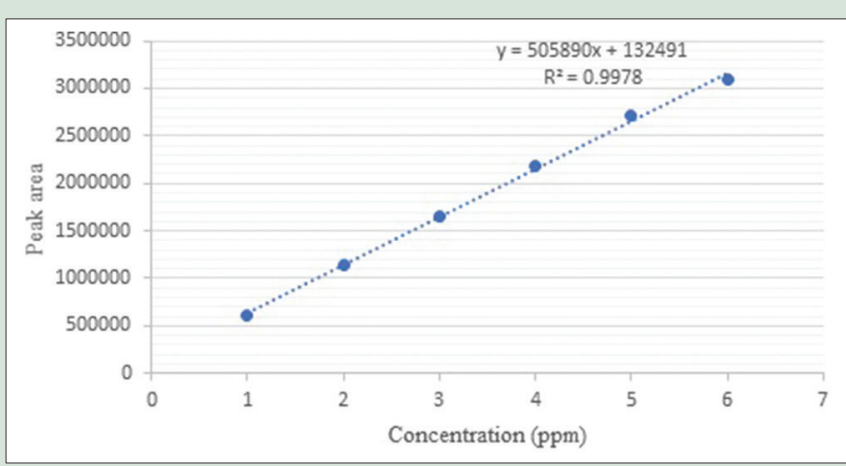

Figure 3: Calibration curve of veratric acid

RSD values are $<5.0 \%$, so the method found to be highly precise and reproducible. The percentage recovery was calculated from differences between the peak areas obtained for spiked and standard solutions, as shown in Table 2 . The accuracy of the method was evaluated by adding the standard solution of 3,4 , and $5 \mathrm{ppm}$ (i.e., $0.3,0.4$, and $0.5 \mathrm{ml}$ ) to known concentration of sample solutions and recovery was found to be $82.20 \%, 97.65 \%$, and $95.17 \%$, respectively. The average \% RSD at three different levels spiked sample of veratric acid was found to be $0.576 \%$, $0.676 \%$, and $0.584 \%$, respectively. Therefore, LC-MS/MS method can be regarded as selective, accurate, and precise for the validation of the veratric acid.

The scavenging of the stable DPPH radical by an antioxidant is a widely used method to evaluate the antioxidant activity in a relatively short time compared with other methods. The effect of antioxidants on DPPH radical scavenging was thought to be due to their hydrogen atom donating ability. In this study, the percentage radical scavenging activity of the ascorbic acid was found to be 13.53, 25.47, 40.76, 56.22, and 72.42 , whereas the quality control sample showed 6.61, 14.64, 20.36, 28.35, and 33.84 at 5, 10,15,20, and $25 \mu \mathrm{g} / \mathrm{ml}$ concentrations, respectively [Table 3]. The lower the absorbance of the reaction mixture indicates higher free radical scavenging activity. The half-maximal inhibitory concentration value for the DPPH radical scavenging activity of ascorbic acid and QC sample was found to be 17.79 and 36.44 , respectively. This indicates that T. avellanedae exhibited strong $\mathrm{DPPH}$ radical scavenging activity.

\section{CONCLUSION}

The developed LC-MS/MS method is simple, precise, specific, and accurate and was proved to be suitable for veratric acid quantification in T. avellanedae. T. avellanedae exhibited strong DPPH radical scavenging activity. Further explorations are needed to investigate the standardization of individual phytoconstituents of T. avellanedae.

\section{Acknowledgements}

The authors are grateful to the all members of Analytical Research and Development at Vidya Herbs Pvt. Ltd., Bengaluru, for their cooperation and technical help. 
Table 3: 1,1-diphenyl-2-picrylhydrazyl radical scavenging activity

\begin{tabular}{lcc}
\hline \multirow{2}{*}{$\begin{array}{l}\text { Conc } \\
(\mu \mathrm{g} / \mathrm{ml})\end{array}$} & \multicolumn{2}{c}{ Percentage of DPPH radical scavenging property } \\
\cline { 2 - 3 } & Ascorbic acid & Quality control sample \\
\hline 5 & $13.57 \pm 0.17$ & $06.54 \pm 0.07$ \\
10 & $25.46 \pm 0.10$ & $14.35 \pm 0.14$ \\
15 & $40.22 \pm 0.12$ & $20.33 \pm 0.09$ \\
20 & $56.33 \pm 0.07$ & $28.24 \pm 0.10$ \\
25 & $72.23 \pm 0.08$ & $33.83 \pm 0.08$ \\
\hline
\end{tabular}

Values are express as mean \pm SD $(n=3)$. SD: Standard deviation;

DPPH: 1,1-diphenyl-2-picrylhydrazyl

\section{Financial support and sponsorship}

Nil.

\section{Conflicts of interest}

There are no conflicts of interest.

\section{REFERENCES}

1. Mahtab AK. Introduction and Importance of Medicinal Plants and Herbs. National Health Portal of India; 2016.

2. World Health Organization. WHO Traditional Medicine Strategy. Geneva: World Health Organization; 2013. p. 2014-23.

3. Ueda S, Umemura T, Dohguchi K, Matsuzaki T, Tokuda H, Nishino H, et al. Production of anti-tumour-promoting furanonaphthoquinones in Tabebuia avellanedae cell cultures. Phytochemistry 1994;36:323-5.

4. Casinovi CG, Marini bettolo GB, Limaog DA, Daliamaia ME, D Albuquerque IL. On quinones isolated from the wood of Tabebuia avellanedae lor. ex griseb. Rend Ist Sup Sanit 1963;26:5-10.

5. Park JG, Yi YS, Hong YH, Yoo S, Han SY, Kim E, et al. TabetriTM (Tabebuia avellanedae Ethanol Extract) ameliorates osteoarthritis symptoms induced by monoiodoacetate through its anti-inflammatory and chondroprotective activities. Mediators Inflamm 2017;2017:3619879.

6. Park JG, Yi YS, Han SY, Hong YH, Yoo S, Kim E, et al. TabetriTM (Tabebuia avellanedae Ethanol Extract) ameliorates atopic dermatitis symptoms in mice. Mediators Inflamm 2018;2018:9079527.

7. Park JG, Son YJ, Kim MY, Cho JY. Syk and IRAK1 contribute to immunopharmacological activities of anthraquinone-2-carboxlic acid. Molecules 2016;21. pii: E809.

8. Zhang L, Hasegawa I, Ohta T. Anti-inflammatory cyclopentene derivatives from the inner bark of Tabebuia avellanedae. Fitoterapia 2016;109:217-23.

9. Woo HJ, Choi YH. Growth inhibition of A549 human lung carcinoma cells by beta-lapachone through induction of apoptosis and inhibition of telomerase activity. Int J Oncol 2005;26:1017-23.

10. Lee EJ, Ko HM, Jeong YH, Park EM, Kim HS. $\beta$-Lapachone suppresses neuroinflammation by modulating the expression of cytokines and matrix metalloproteinases in activated microglia. J Neuroinflammation 2015;12:133.

11. $\mathrm{Xu} \mathrm{J,} \mathrm{Wagoner} \mathrm{G,} \mathrm{Douglas} \mathrm{JC,} \mathrm{Drew} \mathrm{PD.} \beta$-Lapachone ameliorization of experimental autoimmune encephalomyelitis. J Neuroimmunol 2013;254:46-54.

12. Machado TB, Pinto AV, Pinto MC, Leal IC, Silva MG, Amaral AC, et al. In vitro activity of Brazilian medicinal plants, naturally occurring naphthoquinones and their analogues, against methicillin-resistant Staphylococcus aureus. Int J Antimicrob Agents 2003;21:279-84.

13. Pereira EM, Machado Tde B, Leal IC, Jesus DM, Damaso CR, Pinto AV, et al. Tabebuia avellanedae naphthoquinones: Activity against methicillin-resistant staphylococcal strains, cytotoxic activity and in vivo dermal irritability analysis. Ann Clin Microbiol Antimicrob 2006;5:5

14. Choi BT, Cheong J, Choi YH. beta-lapachone-induced apoptosis is associated with activation of caspase-3 and inactivation of NF-kappaB in human colon cancer HCT-116 cells. Anticancer Drugs 2003;14:845-50.

15. Byeon SE, Chung JY, Lee YG, Kim BH, Kim KH, Cho JY. In vitro and in vivo anti-inflammatory effects of taheebo, a water extract from the inner bark of Tabebuia avellanedae. J Ethnopharmacol 2008;119:145-52.

16. Lee MH, Choi HM, Hahm DH, Her E, Yang HI, Yoo MC, et al. Analgesic and anti-inflammatory effects in animal models of an ethanolic extract of Taheebo, the inner bark of Tabebuia avellanedae. Mol Med Rep 2012;6:791-6.

17. Park BS, Lee HK, Lee SE, Piao XL, Takeoka GR, Wong RY, et al. Antibacterial activity of Tabebuia impetiginosa Martius ex DC (Taheebo) against Helicobacter pylori. J Ethnopharmacol 2006;105:255-62.

18. Pereira IT, Burci LM, da Silva LM, Baggio CH, Heller M, Micke GA, et al. Antiulcer effect of bark extract of Tabebuia avellanedae: Activation of cell proliferation in gastric mucosa during the healing process. Phytother Res 2013;27:1067-73.

19. ICH (Q2B) Note for Guidance on Validation of Analytical Procedures. Methodology, Geneva, Switzerland: IFPMA, International Conference on Harmonization; 1996.

20. Braca A, De Tommasi N, Di Bari L, Pizza C, Politi M, Morelli I. Antioxidant principles from Bauhinia tarapotensis. J Nat Prod 2001;64:892-5.

21. $\mathrm{ICH}(\mathrm{Q} 2 \mathrm{~A})$ Validation of Analytical Procedures: Text and Methodology. Geneva, Switzerland: International Conference on Harmonization; 2005. 